\section{International Scientific Journal Theoretical \& Applied Science}

p-ISSN: 2308-4944 (print) e-ISSN: 2409-0085 (online)

Year: $2016 \quad$ Issue: 9 Volume: 41

Published: $30.09 .2016 \quad$ http://T-Science.org
Tatjana Ivanovna Kozhedub Assistant of the Department of Zoology, Physiology and Genetics

Gomel State University named Skaryna bimgomel@gmail.com

Denis Nikolaevich Drozdov

Ph.D. in Biological Sciences, Associate Professor Gomel State University named Skaryna

Olga Mihajlovna Hramchenkova Ph.D. in Biological Sciences, Associate Professor Gomel State University named Skaryna

SECTION 11. Biology. Ecology. Veterinary.

\title{
MYCORRHIZALFORMING MAKROMITCETY AS ULCERATIVE CYCLE PHOSPHORUS IN FOREST ECOSYSTEMS
}

\begin{abstract}
The article examines the impact of agrochemical properties of soil phosphorus content in fruiting bodies of forest macromycetes. It was established that the humus content and mobile forms of phosphate in the soil does not have a significant effect on the accumulation of phosphorus macromycetes. It is shown that an increase in the acidity of the soil solution decreases the content of mobile forms of phosphorus in the forest floor, while there is a relatively stable accumulation of phosphates in fruiting fungi bodies' which form mycorrhiza.

Key words: mycorrhiza, makromitcety, phosphorus, the soil, humus content, the acidity of the soil solution.

Language: Russian

Citation: Kozhedub TI, Drozdov DN, Hramchenkova OM (2016) MYCORRHIZALFORMING MAKROMITCETY AS ULCERATIVE CYCLE PHOSPHORUS IN FOREST ECOSYSTEMS. ISJ Theoretical \& Applied Science, 09 (41): 11-16.

Soi: http://s-o-i.org/1.1/TAS-09-41-2 Doi: crossef http://dx.doi.org/10.15863/TAS.2016.09.41.2

\section{МИКОРИЗООБРАЗУЮЩИЕ МАКРОМИЦЕТЫ КАК ЗВЕНО КРУГОВОРОТА ФОСФОРА В ЛЕСНЫХ ЭКОСИСТЕМАХ}

Аннотация: В статье рассматривается влияние агрохимических свойств почв на содержание фосфора в плодовых телах лесных макромищетов. Установлено, что содержание гумуса и подвижных форм фосфатов в почве не оказывает значимого влияния на накопление фосфора макромицетами. В работе показано, что при повышении кислотности почвенного раствора снижается содержание подвижных форм фосфора в лесной почве, при этом наблюдается относительно стабильное накопление фосфатов в карпофорах микоризобразующих грибов.

Ключевые слова: микориза, макромицеть, фосфор, почва, содержание гумуса, кислотность почвенного раствора.
\end{abstract}

\section{Введение}

Микоризообразующие макромицеты играют важную роль в лесных экосистемах, они образуют симбиоз с растениями многих видов, трансформируют в почве соединения элементов минерального питания и переводят их в доступную для поглощения форму. Тем самым они компенсируют дефицит биогенных элементов в лесной экосистеме путем включения этих элементов в биотический круговорот [1-3]. Функциональная роль грибов в процессе круговорота веществ в природе определяется их способностью синтезировать комплекс внеклеточных ферментов, с помощью которых происходит деградация растительного субстрата [4,5]. Ферментативная система эктомикоризных грибов способствует образованию органических кислот, которые содействуют химическому выщелачиванию минеральных поверхностей с последующей мобилизацией $\mathrm{P}, \mathrm{K}, \mathrm{Ca}, \mathrm{Mg}$ и увеличению их доступности для растений [6]. Одним из основных свойств микосимбионтов является способность аккумулировать определенные химические элементы из почвенного субстрата, которые служат фактором, определяющим протекающие в них физиологические и биохимические процессы. В лесной подстилке содержится (до 20 \%) мицелия дикорастущих грибов, который способствует запасанию растворимых полифосфатов и переносу их в растение-хозяин [7].

Способность мобилизации макро- и микроэлементов субстрата обусловлена агрохимическими свойствами почв [6]. Все 
причины, влияющие на аккумуляцию микро- и макроэлементов в макромицетах, изучены не достаточно полно, однако можно выделить основополагающие факторы, среди которых геохимический состав субстрата, $\mathrm{pH}$ почвы, содержание органических веществ, а также факторы, влияющие на подвижность элементов и их доступность для биоты [8].

Одним из важнейших макроэлементов в растительной клетке является фосфор, физиологическая роль которого заключается: в регуляции синтеза белка, деления и развития клеток, механизмах энергетического обмена. Съедобные микориообразующие грибы служат источником фосфора в рационе питания жителей Республики Беларусь [9]. Существует проблема доступности фосфора для растений на различных типах почв. В Гомельской области средневзвешенное содержание фосфора в почвах сельскохозяйственных земель составляет 179 мг/кг [10], для лесных почв предполагаются более низкие значения этого показателя. В регионе преобладают дерново-подзолистые супесчаные и песчаные почвы, образовавшиеся на мелкозернистых песках, часто подстилаемых моренным суглинком. Главным источником соединений фосфора для почв служат почвообразующие породы. Минеральные фосфаты, в частности соли ортофосфорной кислоты, являются основным источником питания для растений и, как правило, преобладают в почве над органическими соединениями. Растворимые формы фосфора представлены в основном двумя группами солей: фосфатами кальция, магния и фосфатами оксидов железа и алюминия. Для почв подзолистого типа характерны фосфаты железа и алюминия. Устойчивость минеральных соединений фосфора (ортофосфатов $\mathrm{Ca}, \mathrm{Al}, \mathrm{Fe}$ ) в значительной степени зависит от почвенных условий: от величины кислотности почвенного раствора, от органического компонента, от гранулометрических характеристик, от влажности и температуры почвы. Повышение кислотности почвенного раствора, способствует понижению подвижных форм фосфора и образованию трудно растворимых фосфорных солей. Фосфор, связанный с органической частью почвы, для растений труднодоступен и используется по мере минерализации органического вещества. Количество наиболее подвижных групп фосфатов увеличивается при переходе от суглинистых почв к песчаным. С уменьшением влажности величина поглощения фосфора возрастает, температура либо ускоряет, либо замедляет физикохимические реакции, непосредственно связанные с процессами поглощения фосфора $[11,12]$.

Для дерново-подзолистых почв Гомельского Полесья с высокой кислотностью характерна низкая подвижность фосфора и сниженная его доступность для растений. Это вызвано образованием нерастворимых соединений фосфора, в частности фосфатов алюминия и железа. Тем не менее, для кислых лесных почв с pH 4-5 богатых грибным мицелием в сравнении с нейтральными и щелочными почвами, сохраняется высокая трансформационная способность, обеспечивающая доступность фосфора и улучшающая плодородие в лесных формациях.

Цель работы состояла в оценке влияния некоторых агрохимических свойств на накопление фосфора микоризообразующими грибами.

\section{Материалы и методы исследования}

Объектом исследований служили микоризообразующие макромицеты и почвенный субстрат лесных насаждений Гомельской области. Были заложены 11 пробных площадей. Пробы съедобных макромицетов и почвы отбирали на территории Терюхского, Макеевского, Грабовского и Романовичского лесничеств Гомельского лесхоза, а также Любанского лесничества Октябрьского лесхоза. Лесничества Гомельского лесхоза расположены преимущественно на дерново-подзолистых слабо и средне оподзоленных супесчаных и песчаных почвах, образовавшихся на мелкозернистых песках, часто подстилаемых на небольшой глубине (в пределах 1 м) моренным суглинком. Для почв характерна кислая и сильнокислая реакция среды, низкое содержание гумуса (с преобладанием фульфокислот), низкая насыщенность основаниями, поглащенные основания в основном $\mathrm{H}^{+}, \mathrm{Al}^{3+}$, содежание фосфора $(0,06-0,08 \%)$ с преобладанием минеральных фосфатов [13]. Любанское лесничество находится на территории дерновоподзолистых заболоченных песчаных и низинных торфяно-болотных почв. Почвы имеют кислую реакцию среды, содержат чаще 3-5, иногда до 7 \% гумуса. Общее его количество существенно растет с увеличением степени гидроморфизма, в целом состав гумуса - гуматно-фульватный, содержание фосфора $(0,05-0,5 \%), \quad$ п преобладанием органических соединений.

На пробных площадях производился отбор проб почвы и сбор образцов дикорастущих грибов. Пробы почв отбирали согласно ГОСТ 28168-89. Общее количество проб составило 55, по пять образцов с каждой площади, из них формировалась усреднённая проба почвы. После высушивания проб каждого стационара проводился химический анализ по определению обменной кислотности, содержанию гумуса и фосфора. Анализ проб почвы выполнялся в соответствии с ГОСТ 26483-85 и ГОСТ 26213-84. Определение кислотности почвы выполнено с помощью рН-метра 150 МИ, Содержание фосфора в почве определяли согласно ГОСТ Р 54650-2011. 


\begin{tabular}{|c|c|c|c|c|c|c|}
\hline Impact Factor: & $\begin{array}{l}\text { ISRA (India) } \\
\text { ISI (Dubai, UAE } \\
\text { GIF (Australia) } \\
\text { JIF }\end{array}$ & $\begin{array}{l}=1.344 \\
=0.829 \\
=0.564 \\
=1.500\end{array}$ & $\begin{array}{l}\text { SIS (USA) } \\
\text { PUHЦ (Russia) } \\
\text { ESJI (KZ) } \\
\text { SJIF (Morocco) }\end{array}$ & $\begin{array}{l}=0.912 \\
=0.234 \\
=1.042 \\
=\mathbf{2 . 0 3 1}\end{array}$ & $\begin{array}{l}\text { ICV (Poland) } \\
\text { PIF (India) } \\
\text { IBI (India) }\end{array}$ & $\begin{array}{l}=6.630 \\
=1.940 \\
=4.260\end{array}$ \\
\hline
\end{tabular}

При сборе грибов учитывался размер плодового тела и их видовой состав. Отбирали грибы следующих видов Boletus edulis Bull., Leccinum scabrum Bull., Leccinum aurantiacum Fr, Cantharellus cibarius Fr.,Russula vesca Fr.Для каждого вида грибов собранного на разных стационарах были сформированы объединенные пробы. После высушивания и озоления каждой пробы определяли содержание фосфора в грибах согласно ГОСТ 26657-97.

Таксационная характеристика типичных древостоев, где были заложены пробные площади, приведена в таблице 1.

Таксационные показатели пробных площадей

Таблица 1

\begin{tabular}{|c|c|c|c|c|c|c|}
\hline \multirow[t]{2}{*}{ ПП } & \multirow[t]{2}{*}{ Состав насаждения } & \multirow{2}{*}{$\begin{array}{c}\text { Возраст, } \\
\text { лет }\end{array}$} & \multirow{2}{*}{$\begin{array}{c}\text { Тип леса/ } \\
\text { эдафоп }\end{array}$} & \multicolumn{2}{|c|}{ Средние } & \multirow{2}{*}{$\begin{array}{c}\text { Полнота } \\
\text { насаждений }\end{array}$} \\
\hline & & & & высота, м & диаметр, см & \\
\hline 1 & 5Б3С2Д & 70 & Б. op./ $/ \mathrm{B}_{2}$ & 26,2 & 27,4 & 0,8 \\
\hline 2 & 8 Б2C & 65 & Б.кис. $/ \mathrm{C}_{2}$ & 28,0 & 28,2 & 0,8 \\
\hline 3 & 5 С5Б+Д & 40 & C. op. $/ \mathrm{B}_{2}$ & 17,1 & 17,4 & 0,7 \\
\hline 4 & 4С3Б1Ос1Д1С & 56 & C.чер./A $/ \mathrm{A}_{3}$ & 19,8 & 20,2 & 0,8 \\
\hline 5 & $7 С 3 Б+Д$ & 50 & С.мш./A 2 & 20,4 & 21,0 & 0,8 \\
\hline 6 & $8 \mathrm{C} 2 Б+Д$ & 26 & С.мш./A & 10,1 & 8,9 & 0,8 \\
\hline 7 & 6С1Д3Б & 30 & C. op. $/ \mathrm{B}_{2}$ & 13,4 & 13,5 & 0,7 \\
\hline 8 & $7 \mathrm{C} 3 \mathrm{~B}$ & 65 & С.мш./A 2 & 24,0 & 26,2 & 0,6 \\
\hline 9 & $6 \mathrm{C} 4 \mathrm{5}$ & 24 & C.вер./A 2 & 7,8 & 8,0 & 0,8 \\
\hline 10 & 7С2Б1Д+Е & 60 & С.кис. $/ \mathrm{C}_{2}$ & 25,4 & 28,0 & 0,9 \\
\hline 11 & $10 \mathrm{C}$ & 40 & C.вер. $/ \mathrm{A}_{2}$ & 12,2 & 12,0 & 0,6 \\
\hline
\end{tabular}

Статистическая обработка результатов химического анализа проводилась с помощью табличного редактора MSOffice Excel 2010. Были использованы методы корреляционного и дескриптивного анализа данных.
Результаты исследований и их обсуждение Результаты оценки агрохимических показателей почвы и содержание фосфора в грибах различных видов представлены в таблице 2.

\section{Свойства лесных почв и содержание фосфора в пробах макромицетов}

Таблица 2

\begin{tabular}{|c|c|c|c|c|c|c|c|c|}
\hline \multirow{2}{*}{ № } & \multirow{2}{*}{$\mathrm{pH}$} & $\begin{array}{c}\text { Гумус, } \\
\text { \% }\end{array}$ & Почва & $\begin{array}{c}\text { Boletus } \\
\text { edulis }\end{array}$ & $\begin{array}{c}\text { Leccinum } \\
\text { scabrum }\end{array}$ & $\begin{array}{c}\text { Leccinum } \\
\text { aurantiacum }\end{array}$ & $\begin{array}{c}\text { Cantharellus } \\
\text { cibarius }\end{array}$ & $\begin{array}{c}\text { Russula } \\
\text { vesca }\end{array}$ \\
\hline 1 & 5,0 & 2,0 & 0,144 & 5,8 & 5,7 & 5,1 & 4,5 & 3,2 \\
\hline 2 & 4,7 & 3,6 & 0,074 & 4,4 & 4,5 & 4,1 & 3,6 & 3,0 \\
\hline 3 & 4,5 & 2,2 & 0,082 & 4,8 & 4,7 & 4,4 & 4,0 & 3,4 \\
\hline 4 & 4,3 & 0,4 & 0,091 & 5,2 & 4,4 & 4,6 & 5,2 & 3,0 \\
\hline 5 & 4,2 & 1,3 & 0,077 & 6,9 & 5,9 & 5,5 & 4,4 & 4,9 \\
\hline 6 & 4,1 & 1,5 & 0,079 & 5,4 & 5,3 & 5,7 & 4,2 & 4,4 \\
\hline 7 & 4,1 & 2,7 & 0,088 & 5,5 & 4,3 & 4,9 & 3,8 & 4,8 \\
\hline 8 & 4,0 & 1,4 & 0,085 & 5,9 & 6,7 & 5,4 & 4,8 & 4,9 \\
\hline 9 & 4,0 & 0,9 & 0,073 & 5,4 & 5,4 & 4,9 & 4,9 & 5,3 \\
\hline 10 & 3,8 & 2,5 & 0,039 & 4,1 & 4,8 & 4,1 & 4,5 & 3,2 \\
\hline 11 & 3,6 & 0,8 & 0,042 & 4,9 & 4,7 & 4,1 & 3,5 & 3,9 \\
\hline
\end{tabular}


Значения кислотности почвы пробных площадей варьировали в диапазоне $3,6 \div 5,0$ (коэффициент вариации 10 \%), содержание гумуса в значительной степени варьировало от 0,4 до 3,6\% (коэффициент вариации 54 \%), концентрация подвижных форм фосфора составила 0, $039 \div$ 0,144 г/кг сухой почвы (коэффициент вариации 35 $\%)$. Данные в таблице 2 сгруппированы по степени увеличения значений кислотности почвы.

Прослеживается общая закономерность снижения содержания подвижных форм фосфора с понижением кислотности почвы. Значение коэффициента корреляции составило 0,81 $(\mathrm{p}<0,05)$.

Достоверной зависимости между содержанием гумуса и подвижных форм фосфора в почве не установлено $(\mathrm{R}<0,1)$.

Корреляционный анализ между содержанием фосфора в грибах и почве позывает, что содержание подвижных форм фосфора в лесных почвах не оказывает значимого влияния на коэффициент накопления фосфора в плодовых телах грибов разных видов. Так коэффициент корреляции между содержанием подвижных форм фосфора в почве и в карпофорах Boletus edulis составил (-0,34), Leccinum scabrum (- 0,29), Leccinum aurantiacum (- 0,27), Cantharellus cibarius (- 0,53 ) u Russula vesca (- 0,31).

Между грибами разных видов не установлено достоверного различия по содержанию фосфора ( $>0,05)$, вариация составила $18 \%$, что указывает на однородность выборки. Проанализировав результаты содержания фосфора в грибах по видовому составу можно сказать о незначительной вариации этого показателя. На рисунке 1 представлены распределения содержания фосфора в грибах разных видов.



Рисунок 1 - Содержание фосфора в плодовых телах макромицетов.

Значения коэффициентов вариации изменялось от 12 - $22 \%$, для Leccinum aurantiacum $12 \%$, Cantharellus cibarius $13 \%$, Boletus edulis $14 \%$, Leccinum scabrum $15 \%$ до Russula vesca $22 \%$. Среднее содержание фосфора в пробах грибов составило 4,71 $\pm 0,85$ г/кг сухого вещества.

На рисунке 2 показано отношение концентрации фосфора, приведенное к средней в макромицетах и в почвенных образцах с различной кислотностью. $\mathrm{C}$ повышением кислотности почвенного раствора наблюдалось снижение содержания подвижных форм фосфора на опытных участках, при этом концентрация фосфатов в грибах менялась не значительно.
Зависимость содержания доступных форм фосфатов в почве от $\mathrm{pH}$ почвенного раствора имеет линейный характер, хорошо описывается линейным уравнением регрессии $\mathrm{R}^{2}=0,82$. Не установлено зависимости между содержанием фосфора в грибах и кислотностью почвы $\mathrm{R}^{2}=$ 0,04. Так же не наблюдалось достоверной связи между содержанием фосфора в грибах и содержанием его в дерново-подзолистых почвах. Можно предположить, что высокая ферментативная активность микоризообразующих грибов, являются важными факторами перевода в почве малорастворимых соединений фосфора в доступные формы [4]. 


\begin{tabular}{l|lrl|l|ll} 
& ISRA (India) & $=\mathbf{1 . 3 4 4}$ & SIS (USA) & $=\mathbf{0 . 9 1 2}$ & ICV (Poland) & $=\mathbf{6 . 6 3 0}$ \\
Impact Factor: & ISI (Dubai, UAE) $=\mathbf{0 . 8 2 9}$ & PVHU (Russia) $=\mathbf{0 . 2 3 4}$ & PIF (India) & $=\mathbf{1 . 9 4 0}$ \\
& GIF (Australia) & $\mathbf{0 . 5 6 4}$ & ESJI (KZ) & $=\mathbf{1 . 0 4 2}$ & IBI (India) & $\mathbf{4 . 2 6 0}$
\end{tabular}



Рисунок 1 - Влияние рН почвенного раствора на величину содержания фосфора в системе почва грибы.

\begin{abstract}
Заключение
Агрохимические свойства почвы содержание гумуса, кислотность почвы, содержание подвижных форм фосфора не оказывает значимого влияния на накопление фосфора макромицетами. Показано стабильное накопление фосфора в плодовых телах микоризообразующих грибов разных видов в
\end{abstract}

среднем на уровне 4,7 г/кг. Полученные данные указывают на наличие общего механизма фосфорного обмена у высших микоризообразующих грибов, обитающих в лесных экосистемах.

\section{References:}

1. Gucia M (2012) Multivariate analysis of mineral constituents of edible Parasol Mushroom (Macrolepiota procera) and soils beneath fruiting bodies collected from Northern Poland/ M. Gucia, A.K. Kojta, G. Jarzyńska, E. Rafał, M. Roszak, I. Osiej, J. Falandysz //Environ Sci Pollut Res. 2012;19:416-431.

2. Kosmachevskaja LN (2009) Arbuskuljarnovezikuljarnaja mikoriza: ee izuchenie i primenenie dlja povyshenija plodorodija pochv / L. N. Kosmachevskaja// AgroJekoInfo. 2009. No2. - pp. 15.

3. Auge RM (2001) Water relations, drought and vesicular-arbuscular mycorrhizal Symbiosis/ R.M.Auge //. Mycorrhiza, 2001.-V. 11. N.3. 42 p.

4. (2012) Flora Belarusi. Griby : v 7 t. T. 1.Boletales. Amanitales. Russulales / Nacional'naja akademija nauk Belarusi, Institut jeksperimental'noj botaniki im. V. F. Kuprevicha; [O. S. Gapienko, Ja. A. Shaporova]
; pod obshh. red. V. I. Parfenova. - Minsk : Belaruskaja navuka, 2012. - 199p.

5. Baldrian P (2008) Chapter 2: enzymes of saprotrophic basidiomycetes. In: Boddy L, Frankland JC, van West P (eds) Ecology of saprotrophic Basidiomycetes. British Mycological Society Symposia Series, 2008.vol. 28. Elsevier, Amsterdam, pp. 19-41.

6. Falandysz J (2013) Macro and trace mineral constituents and radionuclides in mushroomshealth benefits and risks / J. Falandysz, J. Borovička // Applied Microbiology and Biotechnology, 2013.vol. 97, no. 2, pp. 477-501.

7. Olsen RA (1990) Soil fungi and the fate of radiocaesium in the soil ecosystem - a discussion of possible mechanisms involved in the radiocaesium accumulation in fungi, and the role of fungias a Cs-sink in the soil // R.A. Olsen, E. Joner, L.R. Bakken. / Transfer of Radionuclides in Natural and Semi-Natural Environment G. Desmetetal., ed. - London - 


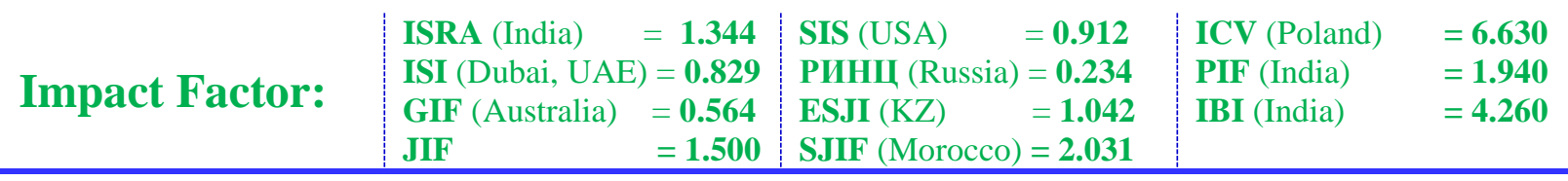

New-York : Elsevier Applied Science, 1990. pp. 202-209.

8. Kabata-Pendias A (1989) Mikrojeleienty v pochvah i rastenijah / A. Kabata-Pendias, H. Pendias -Moscow: Mysl', 1989. -439 p.

9. Kozhedub TI (2016) Dikorastushhie makromicety kak istochnik fosfora $\mathrm{v}$ pitanii naselenija Belarusi/ T.I. Kozhedub// Problemy zdorov'ja i jekologii. - 2016 - №2(48) - p.8690 .

10. (2012) Nacional'naja sistema monitoringa okruzhajushhej sredy Respubliki Belarus': rezul'taty nabljudenij, 2012 // Pod obshhej redakciej S. I. Kuz'mina. [Jelektronnyj resurs].
Jelektronnye, tekstovye, graficheskie dannye. (173 Mb), - Minsk RUP «Bel NIC «Jekologija», 2013;

11. Aderihin PG (1970) Fosfor v pochvah i zemledelii Central'no-Chernozemnoj polosy / P.G. Aderihin - Voronezh, 1970. - 248 p.

12. Titova VI (2005) Fosfor $v$ zemledelii Nizhegorodskoj oblasti / V.I. Titova, O.D. Shafronov, L.D. Varlamova// Nizhegorodskaja gos. s.-h. akademija. - N. Novgorod: Izd-vo VVAGS, 2005. - 219 p.

13. Marchik TP (2006) Pochvovedenie s osnovami rastenievodstva : ucheb. posobie / T.P. Marchik, A.L. Efremov. - Grodno : GrGU, 2006. - 249p. 